\title{
Soldagem Dissimilar da Liga de Alumínio 5052 H34 e do Aço SAE 1020 pelo Processo Hybrid Friction Stir Welding Assistido por Plasma: Análise da Resistência Mecânica, do Desgaste da Ferramenta e dos Esforços de Soldagem
}

\author{
Bruno Silva Cota $^{1}$ (D), Alexandre Queiroz Bracarense ${ }^{2}$ (iD) \\ 1 Universidade Federal de Itajubá - UNIFEI, Instituto de Engenharias Integradas, Itabira, MG, Brasil. \\ 2 Universidade Federal de Minas Gerais - UFMG, Departamento de Engenharia Mecânica, Laboratório de Robótica, Soldagem e Simulação - LRSS, Belo \\ Horizonte, MG, Brasil.
}

Como citar: Cota BS, Bracarense AQ. Soldagem Dissimilar da Liga de Alumínio 5052 H34 e do Aço SAE 1020 pelo Processo Hybrid Friction Stir Welding Assistido por Plasma: Análise da Resistência Mecânica, do Desgaste da Ferramenta e dos Esforços de Soldagem. Soldagem \& Inspeção. 2020;25:e2509. https://doi.org/10.1590/0104-9224/SI25.09

\begin{abstract}
Resumo: Esta pesquisa tratou da primeira aplicação do processo Hybrid Friction Stir Welding na soldagem dissimilar alumínio-aço com a utilização de uma fonte de pré-aquecimento por plasma. Um dos benefícios em se utilizar o pré-aquecimento da junta é a possibilidade de coalescer o material e reduzir sua resistência mecânica, viabilizando assim a utilização de ferramentas fabricadas em aço, além de tornar a mistura mais eficiente por meio da introdução da ferramenta diretamente na interface de soldagem (Offset igual a zero). Nesta pesquisa, foram realizadas juntas soldadas a topo do aço carbono SAE 1020 e da liga de alumínio 5052 H34 com $3 \mathrm{~mm}$ de espessura utilizando um cabeçote desenvolvido especialmente para essa aplicação, que foi adaptado a um robô antropomórfico COMAU NJ5000 de 6 graus de liberdade e capacidade de $500 \mathrm{~kg}$. O pré-aquecimento das amostras foi realizado pela adaptação de uma máquina de corte a plasma, em que a temperatura e a corrente foram variadas em: $0{ }^{\circ} \mathrm{C}$ (sem pré-aquecimento), $250{ }^{\circ} \mathrm{C}(40 \mathrm{~A}), 350{ }^{\circ} \mathrm{C}(50 \mathrm{~A})$ e $450{ }^{\circ} \mathrm{C}(60 \mathrm{~A}) .0$ deslocamento da ferramenta (offset) foi variado em zero e $-2,5 \mathrm{~mm}$. Foi identificado o aumento da resistência mecânica das juntas com o aumento da temperatura de pré-aquecimento. Quando a temperatura de pré-aquecimento foi de $450{ }^{\circ} \mathrm{C}$ houve o aumento de aproximadamente $111 \%$ da resistência mecânica quando comparado ao processo sem pré-aquecimento. Foi verificado também a redução dos esforços de soldagem e do desgaste da ferramenta com o aumento da temperatura de pré-aquecimento.
\end{abstract}

Palavras-chave: Friction stir welding; Híbrido; Soldagem; Robotizado; Dissimilar; Pré-aquecimento.

\section{Hybrid Friction Stir Welding Process with Plasma-assisted of 5052 H34 Aluminum Alloy and SAE 1020 Steel: Analysis of Mechanical Strength, Tool Wear and Welding Stresses}

\begin{abstract}
This research addressed the first application of the Hybrid Friction Stir Welding process using plasma preheating source in aluminum-steel welding. One of the benefits of using joint preheating is the possibility of coalescing the material and reducing its mechanical resistance, thus making possible the use of tools made of steel, in addition to making the mixing more efficient by introducing the tool directly into the welding interface. In this research, welded joints of SAE 1020 carbon steel and aluminum alloy $5052 \mathrm{H} 34$ with $3 \mathrm{~mm}$ thick plates were made using a specially designed head for this application, which was adapted to a COMAU NJ5000 anthropomorphic robot of 6 degrees of freedom and capacity of $500 \mathrm{~kg}$. The samples were preheated by the adaptation of a plasma cutting machine, where the temperature and the current were varied in: $0{ }^{\circ} \mathrm{C}, 250^{\circ} \mathrm{C}(40 \mathrm{~A}), 350^{\circ} \mathrm{C}(50 \mathrm{~A})$ and $450{ }^{\circ} \mathrm{C}(60 \mathrm{~A})$. The displacement of the tool (offset) was varied in zero and $-2.5 \mathrm{~mm}$. The increase in the mechanical strength of the joints with the increase of the preheating temperature was identified. When the preheating temperature was $450^{\circ} \mathrm{C}$ there was an approximately $111 \%$ increase in mechanical strength compared to the process without preheating. It has been possible to reduce welding efforts and tool wear by increasing the preheat temperature.
\end{abstract}

Key-words: Friction stir welding; Hybrid; Welding; Robotic; Dissimilar; Preheating. 


\section{Introdução}

O processo de soldagem por atrito com pino não consumível (SAPNC), mais conhecido como Friction Stir Welding (FSW), foi inventado por Wayne Thomas e um time de pesquisadores no início da década de 1990 em Cambridge, no Reino Unido [1]. O TWI (The Welding Institute), onde a técnica foi criada, é uma das organizações de pesquisa e tecnologia independentes mais importantes do mundo, com experiência em união de materiais e processos de engenharia aplicados na indústria.

As aplicações industriais do processo Friction Stir Welding (FSW) na soldagem de materiais metálicos leves (com baixa temperatura de fusão), como ligas de alumínio e magnésio, são diversas e se concentram hoje principalmente nas indústrias aeronáuticas, automotivas, navais e aeroespaciais. Em contrapartida, as aplicações dessa tecnologia na união de materiais com temperatura de fusão mais elevada, como ligas a base de cobre, ferro e níquel, são ainda escassas, pois a tecnologia está em desenvolvimento e existem limitações relacionadas aos materiais utilizados para fabricação das ferramentas e desgaste prematuro das mesmas [2].

Alguns pesquisadores já estudaram a utilização de variadas fontes externas de calor para auxiliarem na soldagem pelo processo Friction Stir Welding, visando reduzir o desgaste da ferramenta pelo atrito, reduzir os esforços de soldagem, viabilizar a soldagem de materiais com maior temperatura de fusão e reduzir o tempo de soldagem [3-10]. Entretanto, não foram encontradas pesquisas sobre a utilização do plasma como fonte de pré-aquecimento para a soldagem dissimilar entre ligas de alumínio e aço. Além disso, não foram encontrados na literatura trabalhos relacionados à utilização de robôs para a soldagem híbrida pelo processo Friction Stir Welding.

Cabage [3] adicionou uma fonte de soldagem a laser ao processo FSW e verificou a queda de $50 \%$ das forças envolvidas no processo. Casavola et al. [4] variaram a distância entre a fonte de calor e a ferramenta FSW em 20 e $40 \mathrm{~mm}$. Além disso, alteraram a potência do laser em $500 \mathrm{~W}$ e $1000 \mathrm{~W}$ durante a soldagem da liga de alumínio 5754 H111 de 6 mm de espessura. De acordo com os autores, a potência de $500 \mathrm{~W}$ e distância de $20 \mathrm{~mm}$ foram ideais para a soldagem da liga em questão. Choi et al. [5] utilizaram um gás aquecido como fonte externa para a soldagem do aço SK5 de 4 mm de espessura e com elevado teor de carbono (0,84\% de C), utilizando uma ferramenta de carboneto de tungstênio (WC-Co). Segundo os autores, foi possível reduzir a estrutura martensítica nas amostras soldadas com aquecimento, uma vez que houve um arrefecimento mais lento. Kou e Cao [6] reivindicam a patente de um dispositivo para a soldagem pelo processo Friction Stir Welding, que inclui a utilização de uma tocha TIG (Tungsten Inert Gas). SchegImann et al. [7] reivindicam o método e um dispositivo utilizado na refrigeração simultânea durante a soldagem pelo processo Friction Stir Welding. Razak et al. [8] e Shah et al. [9] utilizaram um maçarico para o pré-aquecimento durante a soldagem dissimilar entre chapas de aço inoxidável e alumínio pelo processo Friction Stir Welding. De acordo com os autores, foi possível aumentar em $80 \%$ a resistência da junta soldada quando comparado ao processo sem pré-aquecimento. Zargar [10] utilizou pré-aquecimento de $150^{\circ} \mathrm{C}, 200^{\circ} \mathrm{C}$ e $250^{\circ} \mathrm{C}$ para a soldagem da liga de alumínio $\mathrm{H} 20$ de $5 \mathrm{~mm}$ de espessura, usando uma fresadora CNC modelo BMV 45 e uma ferramenta de carboneto de tungstênio (WC-Co) com formato triangular. As características da fonte de calor usada no projeto não foram evidenciadas no trabalho, entretanto, verificou-se que a qualidade superficial das amostras e a resistência mecânica aumentaram com o aumento da temperatura de pré-aquecimento.

Diversos autores estudaram a junção dissimilar alumínio-aço pelo processo FSW, sendo que em grande parte dos projetos são usadas ferramentas especiais fabricadas pelo processo da metalurgia do pó [11-16]. Estudos realizados por Fukumoto et al. [14] demonstram que a resistência da junta é maior quando a ferramenta é parcialmente inserida no lado do aço, entretanto, são verificados efeitos indesejáveis como desgaste excessivo e quebra da mesma [11]. Dessa forma, um dos benefícios de se empregar o pré-aquecimento da junta é a possibilidade de coalescer o material e reduzir sua resistência mecânica, viabilizando assim a utilização de ferramentas fabricadas em aço, além de tornar a mistura mais eficiente por meio da introdução desta na interface de soldagem (Offset igual a zero).

De acordo com Capelari e Mazzaferro [17], apesar da técnica de soldagem pelo processo FSW ter merecido destaque, sendo objeto de estudo em diversos centros de pesquisa tecnológica e Universidades do exterior, pouco se tem observado quanto a trabalhos realizados inteiramente no Brasil. De acordo com os autores, um dos motivos para isto certamente reside na necessidade de um alto investimento para a obtenção dos equipamentos específicos à soldagem FSW. Além disso, de acordo com Backer [18], apesar do processo FSW estar sendo objeto de estudo em vários centros de pesquisa no mundo, poucos avaliam sua aplicação em robôs industriais, em que se destacam os institutos e as empresas: HGZ (Helmholtz-Zentrum Geesthacht), IWB e KUKA (em conjunto com o Grupo Airbus), na Alemanha; a ESAB, na Suécia; Institut Maupertuis e Institut de Soudure, na França; Cewac, na Bélgica; Friction Stir Link, nos Estados Unidos. Neste contexto, o maior avanço tecnológico que se tem conhecimento é o desenvolvimento de uma tecnologia robotizada para a soldagem de alumínio e aço, aplicada na produção em série de um veículo pela Honda Motor Co $[19,20]$. Dessa forma, teve-se como motivação deste trabalho utilizar um sistema robotizado para realizar a soldagem pelo processo Friction Stir Welding, em que foram superados os desafios relacionados ao uso desta tecnologia, como necessidade de robustez e torque para a realização das juntas.

Este trabalho tem como objetivo geral caracterizar a resistência mecânica das juntas dissimilares produzidas pela união da liga de alumínio 5052 H34 e do aço SAE 1020 pelo processo Hybrid Friction Stir Welding assistido por plasma, utilizando um robô antropomórfico com 6 graus de liberdade e capacidade de $500 \mathrm{~kg}$. Além disso, foram avaliados os esforços de soldagem, bem como o desgaste da ferramenta. 


\section{Materiais e Métodos}

\subsection{Materiais}

Os materiais empregados neste estudo foram chapas de $125 \times 400 \times 3 \mathrm{~mm}$ de espessura da liga de alumínio $5052 \mathrm{H} 34$ e do aço AISI SAE 1020. A liga de alumínio 5052 H34 possui como principal elemento de liga o magnésio, sendo considerada de excelente soldabilidade e com boa resistência à corrosão, principalmente em atmosfera salina.

A liga de alumínio usada possui propriedades mecânicas correspondentes à condição de tratamento $\mathrm{H3}$, ou seja, deformada plasticamente a frio e estabilizada. De acordo com ABNT NBR [21], são produtos que sofrem deformação plástica a frio e cujas propriedades mecânicas são estabilizadas por um tratamento térmico a baixa temperatura, do qual resulta uma resistência à tração ligeiramente menor e maior ductilidade. O segundo dígito indica o grau de encruamento em ordem crescente, abrangendo os dígitos de 1 a 8. Sendo assim, essa liga apresenta limite de resistência à tração intermediário.

\subsection{Equipamentos}

Para a soldagem dissimilar da liga de alumínio 5052 H34 ao aço AISI SAE 1020 foi utilizado o sistema robótico projetado e validado por Cota e Bracarense [22]. A montagem experimental realizada é apresentada na Figura 1, em que é possível verificar o robô antropomórfico COMAU NJ5000 de 6 graus de liberdade (A) que foi usado para a adaptação do sistema de soldagem dimensionado (B). A base de soldagem é a mesa de uma furadeira de coluna adaptada como estrutura para a fixação das chapas a serem unidas pelo processo FSW (Figura 1C). Para fazer o controle da rotação do sistema de soldagem foi utilizado um inversor de frequência com capacidade de acionamento de motores de até $50 \mathrm{cv}$.

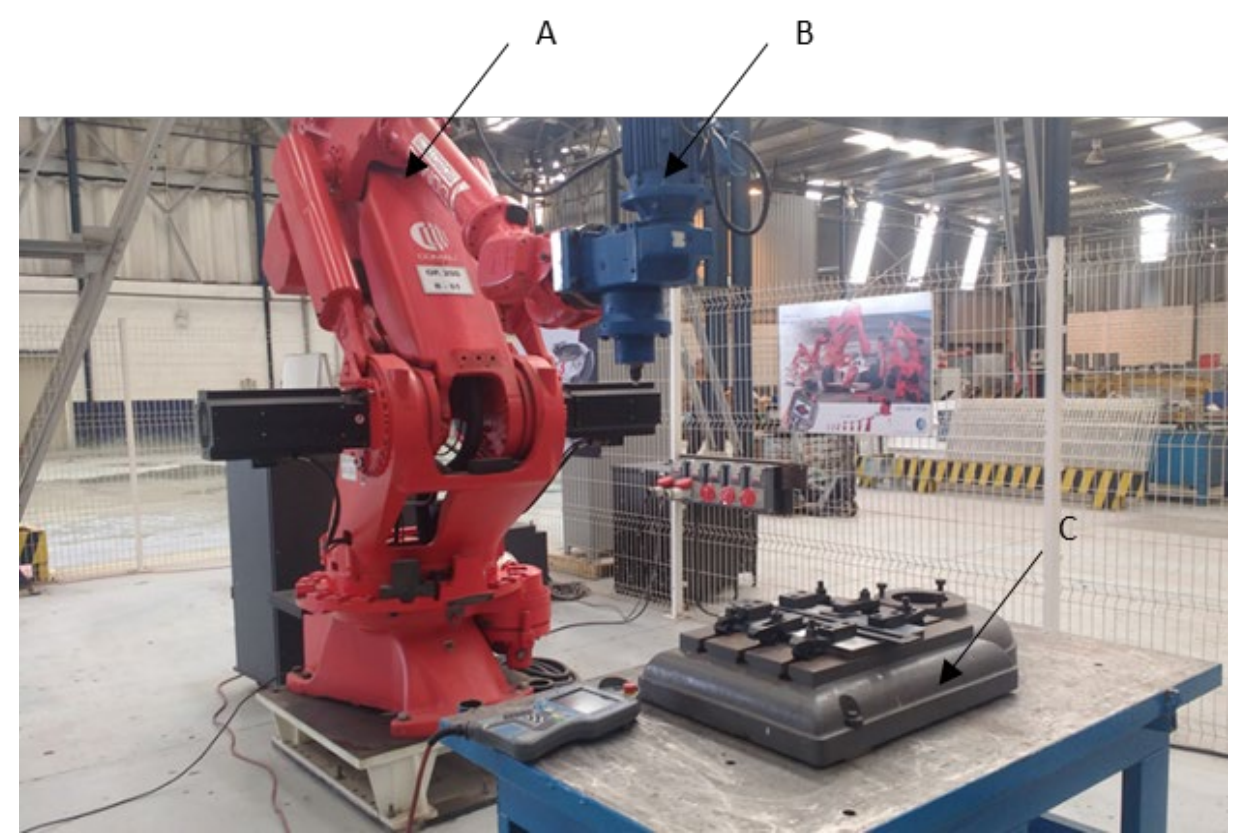

Figura 1. Montagem experimental: (A) Robô antropomórfico COMAU NJ5000; (B) Sistema de soldagem; (C) Base de soldagem.

Para o pré-aquecimento das chapas foi adaptada uma máquina de corte a plasma do fabricante Hyperterm ${ }^{\circledR}$, modelo Powermax 1250. Conforme se apresenta na Figura 2, o equipamento permite operação na faixa de corrente de 25 a $80 \mathrm{~A}$ e pressão do ar de 50 a 80 PSI. Os comandos para o início e o término do pré-aquecimento foram realizados de forma manual, porém remota. $\mathrm{O}$ ar comprimido usado no processo estava livre de contaminantes e umidade, uma vez que passou pela filtragem da linha de abastecimento e pelo filtro do equipamento usado. 


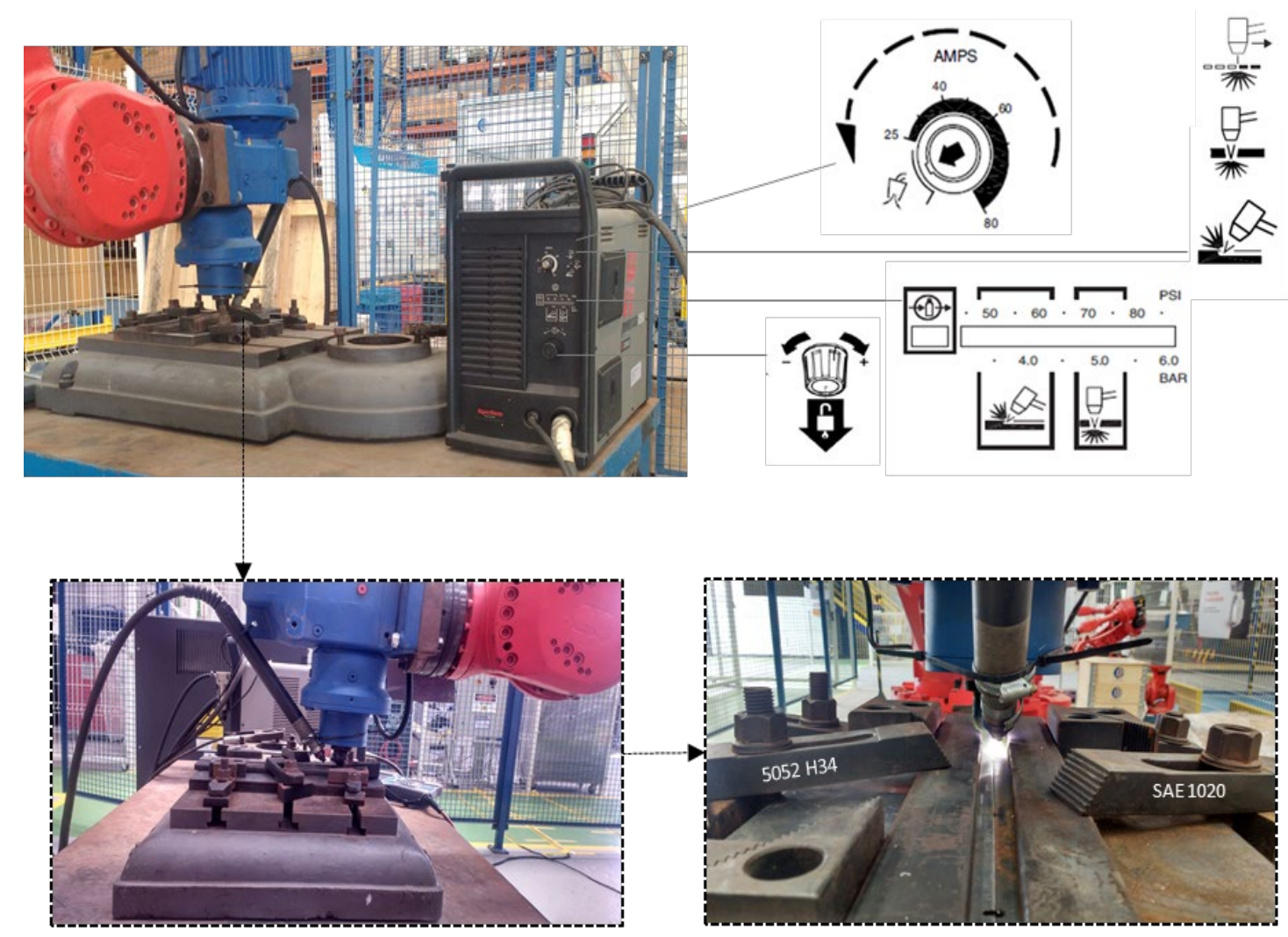

Figura 2. Máquina de corte a plasma Hyperterm ${ }^{\circledR}$, modelo Powermax 1250.

\subsection{Metodologia}

Os parâmetros de soldagem finais são apresentados na Tabela 1, onde foi variada a posição do pino nas chapas (offset) e a temperatura de pré-aquecimento, conforme apresentado esquematicamente na Figura 3 . 0 offset de $-2,5 \mathrm{~mm}$ é o deslocamento da ferramenta para o lado de retrocesso a partir do centro da amostra, tendo como referência o diâmetro médio da ferramenta, visto que o diâmetro maior do pino é de $6 \mathrm{~mm}$ e o menor de $4 \mathrm{~mm}$. A velocidade de soldagem para as amostras sem pré-aquecimento foi de $7,5 \mathrm{~mm} / \mathrm{min}$, sendo a máxima velocidade em que foi possível obter juntas soldadas sem defeitos. Já a velocidade de avanço foi variada para os testes com pré-aquecimento, uma vez que foi possível obter uma redução dos esforços de soldagem. A ferramenta sofreu uma inclinação de $2^{\circ}$, e o tempo de espera (dwell time) antes de iniciar o translado da ferramenta foi de $60 \mathrm{~s}$.

Os valores utilizados para a corrente de pré-aquecimento foram determinados por meio de pré-testes, em que se escolheu aqueles que proporcionaram pré-aquecimento de $250^{\circ} \mathrm{C}, 350^{\circ} \mathrm{C}$ e $450{ }^{\circ} \mathrm{C}$, verificados por meio de um pirômetro digital. Esses valores foram obtidos pelas correntes de pré-aquecimento de $40 \mathrm{~A}, 50 \mathrm{~A}$ e $60 \mathrm{~A}$, respectivamente, quando aquecido o aço SAE 1020 pontualmente por 30 segundos e estabilizado.

Tabela 1. Parâmetros para a soldagem da liga Al 5052 H34 e o aço SAE 1020.

\begin{tabular}{|c|c|c|c|c|c|c|c|}
\hline Teste & $\begin{array}{l}\text { Offset } \\
{[\mathrm{mm}]}\end{array}$ & $\begin{array}{c}\text { Temperatura de } \\
\text { pré-aquecimento } \\
{\left[{ }^{\circ} \mathrm{C}\right]}\end{array}$ & $\begin{array}{l}\text { Corrente de pré- } \\
\text { aquecimento [A] }\end{array}$ & $\begin{array}{l}\text { Velocidade de } \\
\text { avanço } \\
\text { [mm/min] }\end{array}$ & $\begin{array}{c}\text { Rotação } \\
\text { [rpm] }\end{array}$ & $\begin{array}{l}\text { Penetração } \\
\text { [mm] }\end{array}$ & $\begin{array}{l}\text { Inclinação da } \\
\text { ferramenta }\left[{ }^{\circ}\right]\end{array}$ \\
\hline $\begin{array}{l}1 S P \\
2 S P\end{array}$ & $\begin{array}{c}0 \\
-2,5\end{array}$ & 0 & 0 & 7,5 & 500 & 2,9 & 2 \\
\hline $\begin{array}{l}1 \mathrm{CP} 40 \\
2 \mathrm{CP} 40\end{array}$ & $\begin{array}{c}0 \\
-2,5\end{array}$ & 250 & 40 & 10 & 500 & 2,9 & 2 \\
\hline $\begin{array}{l}1 \mathrm{CP} 50 \\
2 \mathrm{CP} 50\end{array}$ & $\begin{array}{c}0 \\
-2,5\end{array}$ & 350 & 50 & 10 & 500 & 2,9 & 2 \\
\hline $\begin{array}{l}1 \mathrm{CP} 60 \\
2 \mathrm{CP} 60\end{array}$ & $\begin{array}{c}0 \\
-2,5\end{array}$ & 450 & 60 & 10 & 500 & 2,9 & 2 \\
\hline
\end{tabular}



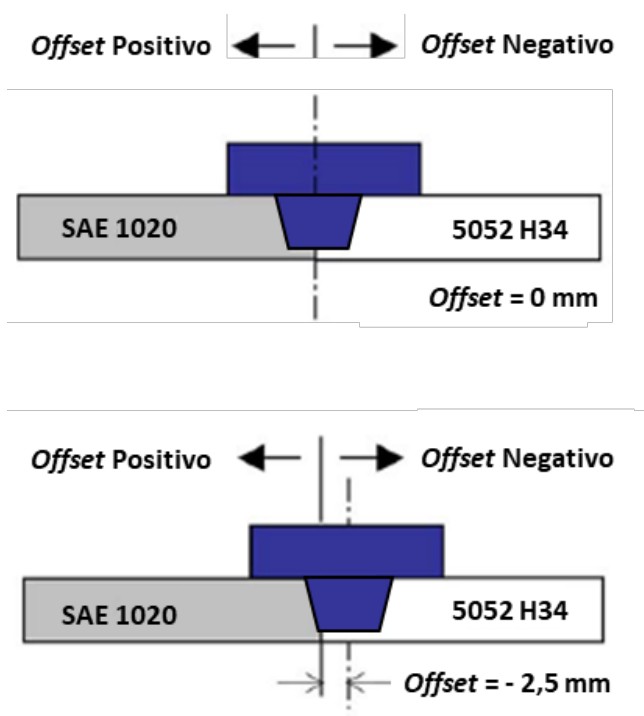

Figura 3. Posicionamento da ferramenta para a soldagem (Offset).

O posicionamento entre a tocha de aquecimento e a chapa de aço é apresentado na Figura 4. Foi mantida a distância de $20 \mathrm{~mm}$ entre a fonte de calor e o ponto em que foi realizada a soldagem, com $15 \mathrm{~mm}$ de altura a partir da chapa de aço (A). $O$ aquecimento foi realizado no lado de avanço, a $2 \mathrm{~mm}$ da junta de soldagem (B). A tocha de aquecimento foi mantida em um ângulo de $60^{\circ} \mathrm{em}$ relação à bancada de soldagem e a pressão do ar foi mantida constante em 55 PSI.

A

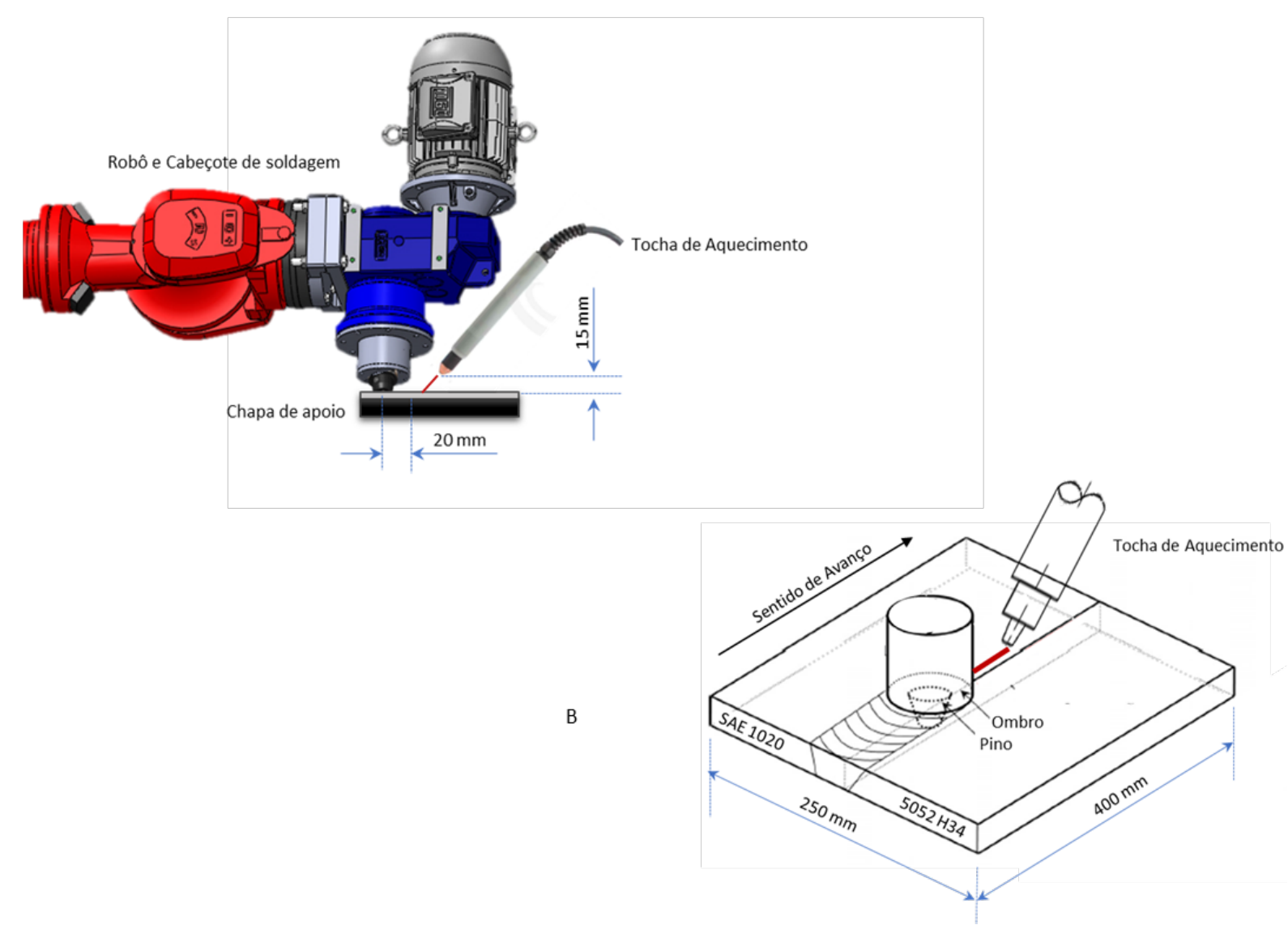

Figura 4. Esquema do posicionamento da tocha de aquecimento em relação às chapas a serem soldadas: (A) Detalhes da montagem experimental evidenciando a distância entre a chapa de apoio, a tocha de aquecimento e o sistema de soldagem; (B) Detalhes da montagem experimental com aquecimento por plasma no lado de avanço. 
As chapas receberam um pré-furo cônico no local onde foi inserida a ferramenta para a soldagem, a fim de reduzir os esforços provenientes do processo de imersão da ferramenta. O pré-aquecimento foi realizado antes da imersão da ferramenta durante um minuto e, após o tempo de espera (dwell time), foi mantido constante até que fosse obtido um cordão com comprimento de $200 \mathrm{~mm}$.

Para a soldagem dos materiais foi utilizada uma ferramenta do material AISI H13, com pino cônico com diâmetro maior de $6 \mathrm{~mm}$, o que contribui para distribuição e redução das forças envolvidas no processo durante a fase de penetração da ferramenta. A dureza média do aço AISI H13 é de 25 HRC, verificada por meio de testes experimentais. Nesta pesquisa, as ferramentas foram submetidas à têmpera e revenimento para proporcionar este aumento. Após a realização dos tratamentos térmicos, foram realizadas dez medições de dureza em diferentes regiões da seção transversal de uma amostra tratada termicamente, em que a média calculada foi de 56 HRC.

Foi utilizada uma ferramenta para cada experimento, sendo realizada a verificação do desgaste percentual por meio da variação do volume do pino da mesma. Para esta análise, após a limpeza dos resíduos por meio de uma escova de aço rotativa, foi realizada a medição das dimensões utilizando um paquímetro da marca Mitutoyo com resolução de 0,02 mm. Em seguida, foi realizada a verificação do volume do cone do pino, por meio da Equação 1.

$$
V=\pi h / 3 \cdot\left[R^{2}+R r+r^{2}\right]
$$

onde: $V$ - Volume $\left(\mathrm{mm}^{3}\right) ; h$ - Altura do tronco de cone $(\mathrm{mm}) ; R$ - Raio da base maior (mm); $r$ - Raio da base menor (mm).

Durante o processo de soldagem, os esforços foram acompanhados por meio da aquisição da corrente elétrica fornecida aos motores aplicados em cada eixo do robô utilizado no estudo. A aquisição foi realizada diretamente pelo Terminal de Programação do Robô (TP - Teach Pendant). Em seguida, foi plotado um gráfico com a média da potência consumida durante o processo, uma vez que a tensão de 600 volts foi constante durante o funcionamento do robô [23].

\subsection{Caracterização das juntas soldadas}

Para cada solda realizada nos testes definitivos foram retiradas três amostras para ensaio de tração (TR1, TR2 e TR3) e outras duas amostras representativas (M1 e M2) para análise metalográfica, medição do perfil de dureza e da rugosidade, conforme apresentado na Figura 5 [2,19,24]. De acordo com a recomendação da norma AWS B4.0-98 "Standard Methods for Mechanical Testing of Welds" [25], os $20 \mathrm{~mm}$ iniciais e finais de cada solda foram descartados.

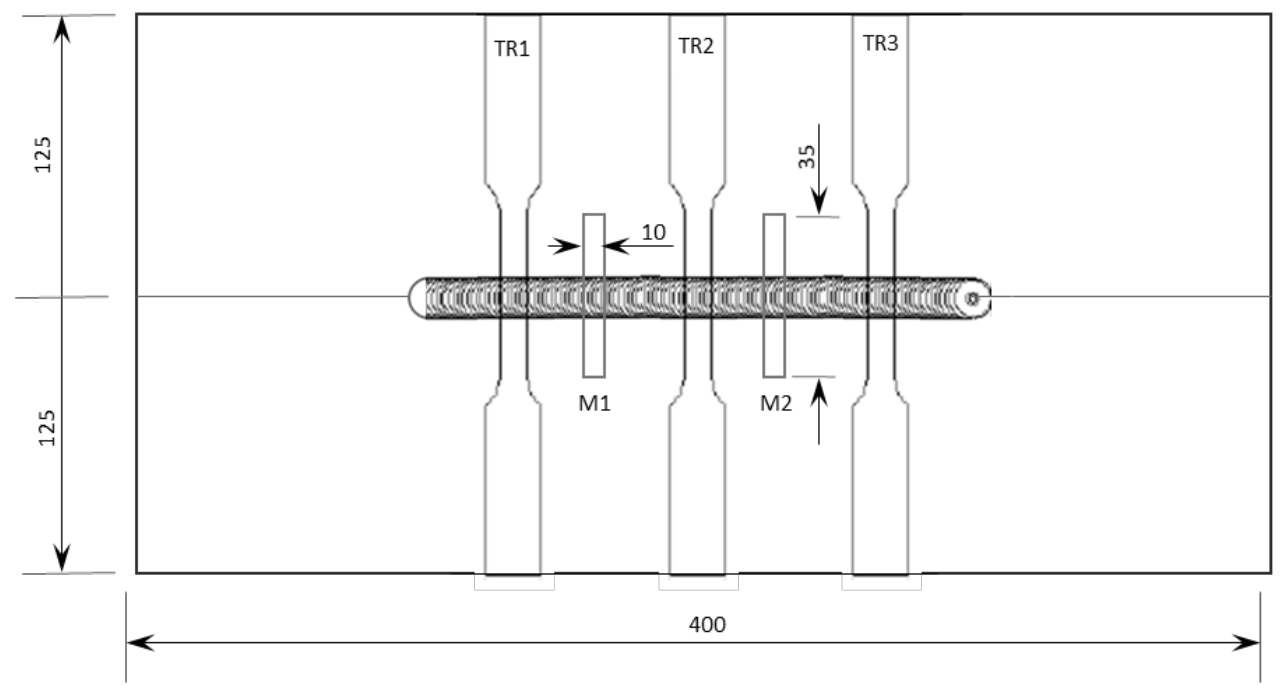

Figura 5. Representação esquemática do posicionamento dos corpos de prova na chapa soldada: TR1, TR2 e TR3 = Corpos de prova para a realização dos ensaios de tração; M1 e M2 = Corpos de prova para a realização dos ensaios de dureza e metalografia.

Para medida da resistência à tração das chapas soldadas foi utilizada a máquina INSTRON, modelo 5982, em que o teste foi executado a uma velocidade de $4,5 \mathrm{~mm} / \mathrm{min}$. As amostras para o ensaio de tração foram confeccionadas conforme norma DIN EN ISO 4136:2013 “Destructive tests on welds in metallic materials - Transverse tensile test" [26], na direção transversal à solda para determinação do limite de resistência à ruptura, escoamento e o alongamento percentual do material após a soldagem. 


\section{Resultados e Discussão}

Está apresentado na Figura 6 a variação da potência média [W] consumida pelos servo motores do robô durante o processo de soldagem para as amostras sem pré-aquecimento e com pré-aquecimento de 250,350 e $450{ }^{\circ} \mathrm{C}$. Verifica-se que para todas as amostras, houve uma redução da potência consumida no início do processo, decorrente do calor gerado pelo atrito e transferência do calor por condução ao longo das chapas, inclusive para a amostra sem pré-aquecimento (Figura 6 - seta A). A redução do consumo energético é mais acentuada para as amostras que sofreram pré-aquecimento, sobretudo para aquela com pré-aquecimento de $450^{\circ} \mathrm{C}$.

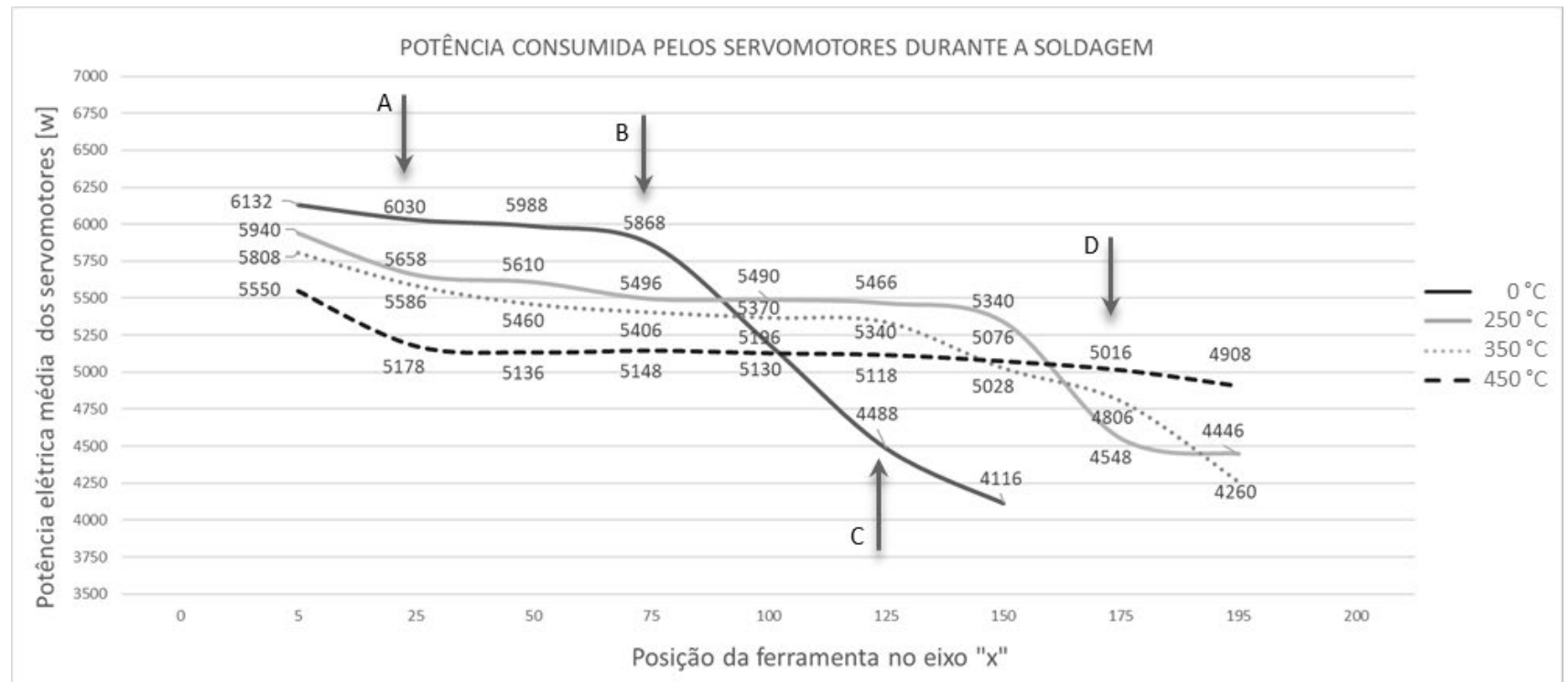

Figura 6. Variação da potência média [W] dos servo-motores do robô durante o processo de soldagem das amostras com e sem pré-aquecimento (Offset igual a zero): (A) Ponto de referência para a indicação da redução dos esforços de soldagem; (B) Ponto de referência para a indicação do desgaste acelerado da amostra soldada sem pré-aquecimento; (C) Ponto de referência para a indicação da continuidade do desgaste da amostra soldada sem pré-aquecimento; (D) Ponto de referência para indicação do desgaste das amostras soldadas com pré-aquecimento de $450^{\circ} \mathrm{C}$.

Para a amostra soldada sem pré-aquecimento foi verificada uma queda brusca do consumo energético entre 75 e $100 \mathrm{~mm}$ do início do processo, decorrente do desgaste da ferramenta (Figura 6 - seta B). Este evento coincide com as marcas apresentadas na região soldada da amostra, em que é possível perceber uma variação dimensional da largura do cordão de solda e da morfologia da rugosidade superficial, o que indica uma perturbação no processo de soldagem, conforme se apresenta na Figura 7. Para esta mesma amostra, a redução do consumo energético foi ainda mais significativa entre 100 e $125 \mathrm{~mm}$ do processo, o que foi associado ao forte desgaste da ferramenta em função do atrito com os materiais base plastificados no estado sólido (Figura 6 - seta C). Dessa forma, conforme se apresenta na Figura 7, houve um desgaste acentuado da ferramenta ao longo do processo, que fez com que grande parte do comprimento do pino se deteriorasse a aproximadamente $90 \mathrm{~mm}$ do processo (seta 1) e houvesse o colapso da ferramenta a cerca de $125 \mathrm{~mm}$ do início do processo (seta 2). A quebra da ferramenta produziu um grande vazio, verificado visualmente na face da solda, evidenciado na Figura 7.

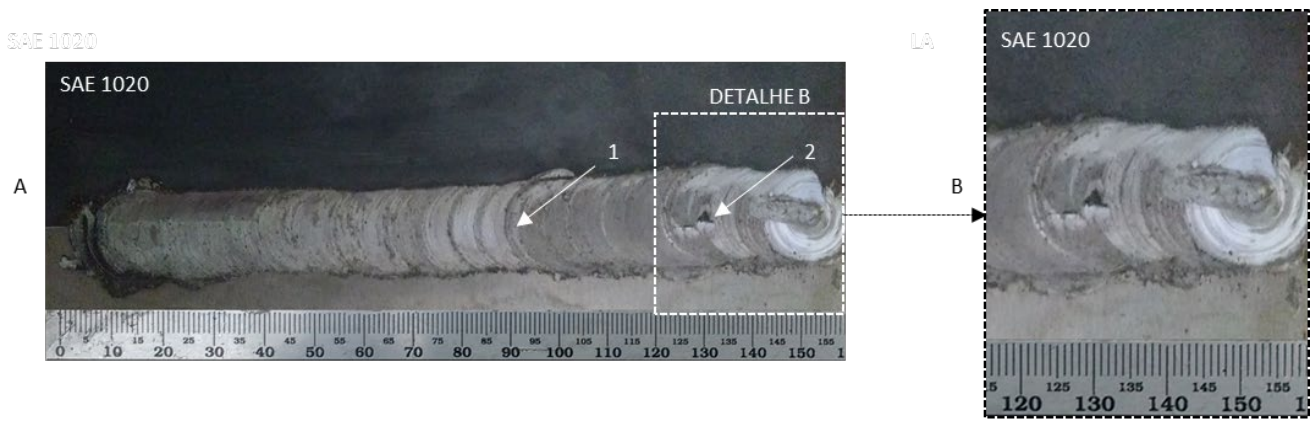

Figura 7. (A) Aspecto superficial da superfície da solda produzida entre a liga de alumínio 5052 H34 e o aço SAE 1020 com 3 mm de espessura sem pré-aquecimento e com offset igual a zero; (B) Detalhe da região em que foi apresentado um vazio superficial em função da quebra da ferramenta. 
São apresentadas na Figura 8 as ferramentas usadas no processo de soldagem de cada amostra. É possível verificar que aquela usada no processo de soldagem sem pré-aquecimento perdeu totalmente o pino durante o processo. Assim como neste trabalho, a quebra de uma ferramenta em aço foi relatada por Chen e Kovacevic [11] durante a soldagem da liga de alumínio 6061 T6 e do aço SAE 1020 com 6 mm de espessura, em que o colapso ocorreu a cerca de 100 mm do início do processo.

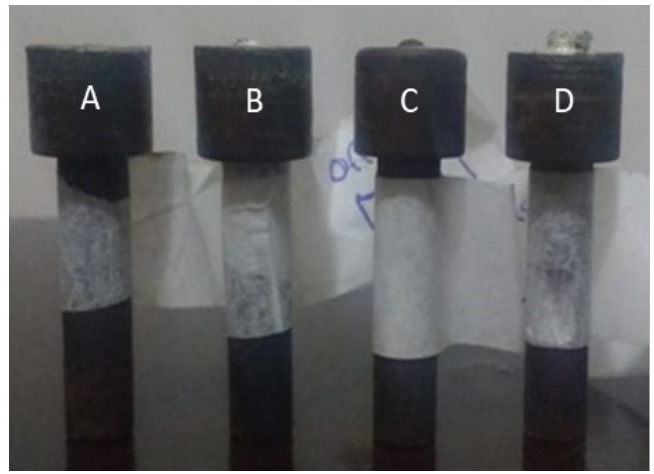

Figura 8. Aspecto das ferramentas após a soldagem dissimilar entre a liga de alumínio $5052 \mathrm{H} 34$ e o aço SAE 1020 com 3 mm de espessura e offset igual a zero: (A) Sem pré-aquecimento; (B) Pré-aquecimento de $250^{\circ} \mathrm{C}$; (C) Pré-aquecimento de $350^{\circ} \mathrm{C}$; (D) Pré-aquecimento de $450^{\circ} \mathrm{C}$.

Para verificar se a quebra da ferramenta foi em função do desgaste da mesma ao longo do processo de soldagem ou em função de um erro de fabricação ou tratamento térmico, foi realizada a repetição do experimento. Como pode ser verificado pela análise da Figura 9, a ferramenta teve seu comprimento reduzido e proporcionou a execução de defeitos externos visíveis a $160 \mathrm{~mm}$ do início do processo. Dessa forma, com a repetição do teste, foi provado que a ferramenta quebrou em função do elevado desgaste devido à utilização do offset igual a zero.

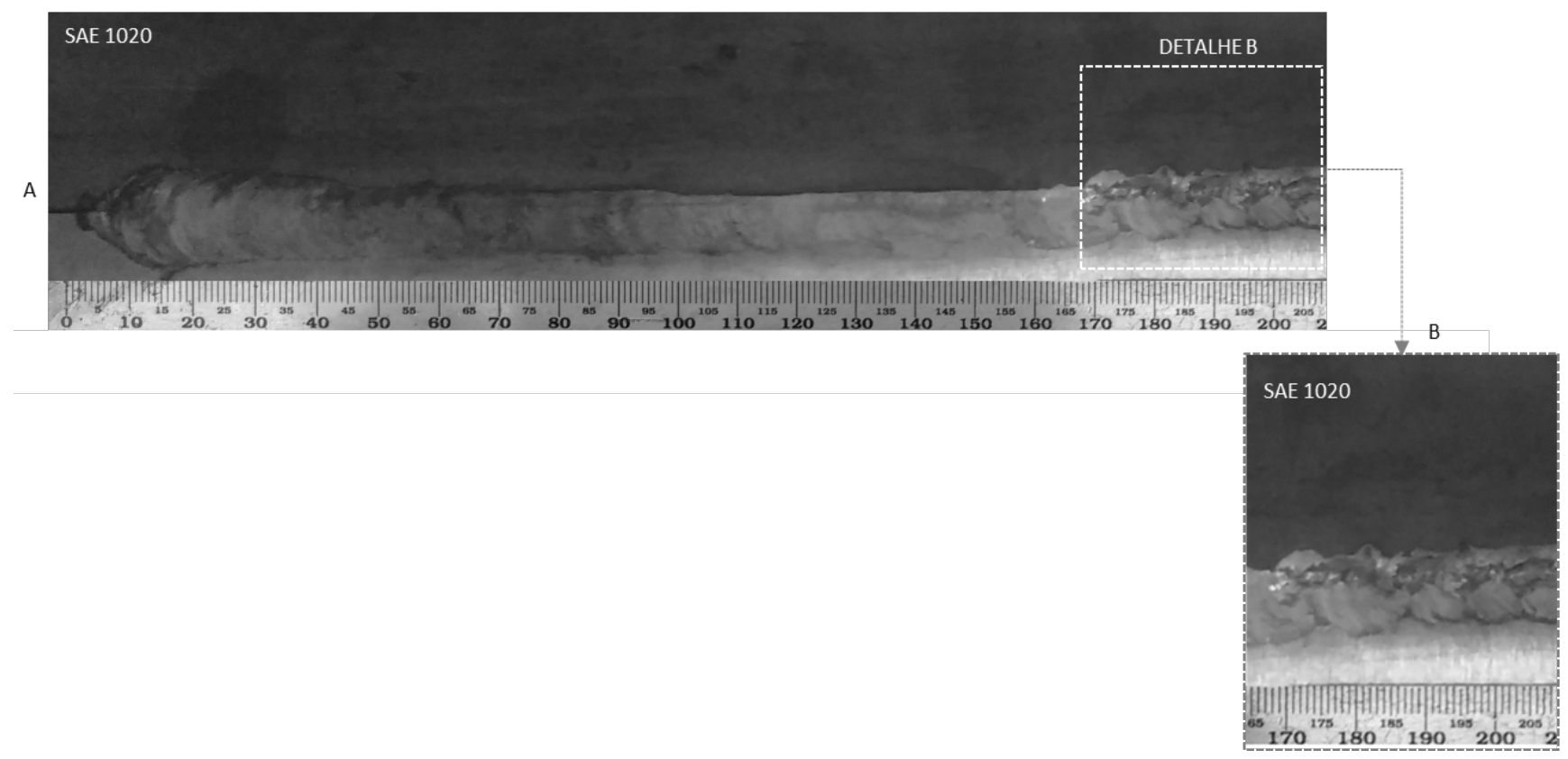

Figura 9. (A) Aspecto superficial da face da solda produzida entre a liga de alumínio 5052 H34 e o aço SAE 1020 com 3 mm de espessura sem pré-aquecimento e com offset igual a zero; (B) Detalhe da região em que foram apresentados defeitos superficiais em função do desgaste da ferramenta.

Em contrapartida, a amostra soldada com pré-aquecimento de $450^{\circ} \mathrm{C}$ permitiu a execução de uma solda livre de defeitos superficiais e com maior resistência mecânica, conforme será descrito a seguir. Assim como para a amostra soldada sem pré-aquecimento, foi verificada uma redução do consumo energético no início do processo, decorrente do maior aquecimento gerado pela radiação do plasma e condução ao longo da chapa a ser soldada. A partir de $25 \mathrm{~mm}$ do início do processo de soldagem, o consumo energético se manteve estável até cerca de $175 \mathrm{~mm}$, quando foi verificado o início da redução deste consumo, proporcionado provavelmente pelo início do desgaste da ferramenta (Figura 6 - seta D). 
As amostras obtidas por meio do teste com pré-aquecimento de $450^{\circ} \mathrm{C}$ apresentaram maior resistência mecânica e menor desvio padrão. Além disso, foi verificado um menor desgaste da ferramenta, com uma redução de cerca de $3,44 \%$ do seu volume. $\mathrm{O}$ desgaste da que foi usada no teste realizado com pré-aquecimento de $450^{\circ} \mathrm{C}$ foi menor que aqueles apresentados por outros autores $[11,27]$.

Diferentemente dos demais ensaios, foi verificada maior aderência do alumínio à ferramenta ao final do processo, decorrente do aumento do aporte térmico (Figura 10). Os resultados apresentados, suportados por aqueles que serão apresentados a seguir sobre o aumento da rugosidade superficial com o aumento da temperatura de pré-aquecimento, corroboram para reforçar a hipótese de que a velocidade de soldagem poderia ter sido aumentada para os testes com pré-aquecimento de $450^{\circ} \mathrm{C}$.

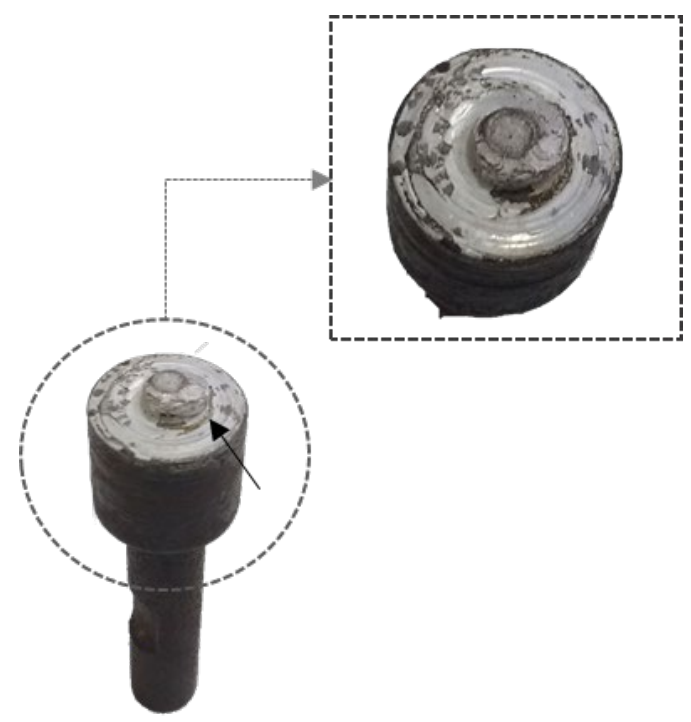

Figura 10. Aspecto da ferramenta após a soldagem dissimilar entre a liga de alumínio 5052 H34 e o aço SAE 1020 com 3 mm de espessura, offset igual a zero e com pré-aquecimento de $450^{\circ} \mathrm{C}$.

Verifica-se, ainda, que as amostras soldadas com pré-aquecimento de 250 e $350{ }^{\circ} \mathrm{C}$ apresentaram tendência semelhante entre si para a variação do consumo energético, com valores ligeiramente menores para a chapa com pré-aquecimento de $350{ }^{\circ} \mathrm{C}$, como pôde ser observado na Figura 6. A resistência mecânica, bem como o desgaste da ferramenta podem ser considerados equivalentes para estas amostras. As ferramentas usadas para a soldagem das amostras com pré-aquecimento de 250 e $350^{\circ} \mathrm{C}$ sofreram redução do volume do pino de aproximadamente $90,47 \%$ e $75,39 \%$, respectivamente.

O desgaste da ferramenta influencia diretamente na morfologia do cordão de solda, bem como na resistência mecânica da junta soldada. As amostras retiradas do final do cordão de solda para a execução dos testes de tração apresentaram resistência mecânica inferiores àquelas retiradas do início do processo.

Com o objetivo de verificar a eficiência das juntas soldadas obtidas pelo processo HFSW, corpos de prova foram submetidos a ensaios de tração, confeccionados e ensaiados conforme as normas e procedimentos descritos na metodologia. A Figura 11 apresenta os resultados dos ensaios mecânicos nas juntas soldadas com pré-aquecimento e sem pré-aquecimento, sendo apresentada também a resistência mecânica da liga de alumínio 5052 H34. Os valores apresentados no gráfico fazem referência à média dos resultados dos testes realizados com os três corpos de prova retirados do início, do meio e do fim do cordão de solda. 


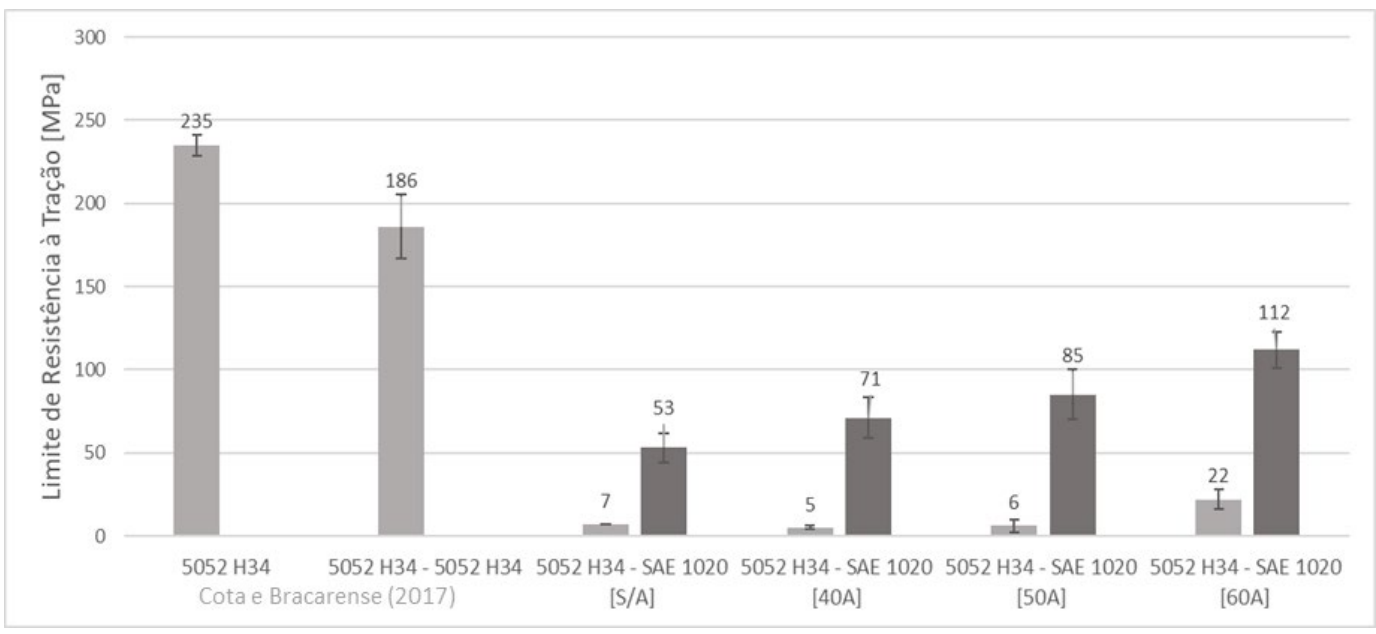

Figura 11. Limite de resistência à tração das amostras produzidas pela soldagem dissimilar da liga 5052 H34 ao aço SAE 1020, unidas sem pré-aquecimento e com pré-aquecimento: Offset = -2,5 mm (cinza claro); Offset = zero (cinza escuro). Comparação com os resultados experimentais da soldagem da liga de alumínio 5052 H34 obtida por [22].

Verifica-se por meio da análise do gráfico a tendência ao aumento da resistência mecânica com o aumento da temperatura de pré-aquecimento, tanto para as amostras soldadas com offset igual a $-2,50 \mathrm{~mm}$, quanto aquelas soldadas com o deslocamento da ferramenta igual a zero.

Para as amostras soldadas com deslocamento da ferramenta de $-2,50 \mathrm{~mm}$, quando a temperatura de pré-aquecimento foi de $450^{\circ} \mathrm{C}$, houve o aumento de aproximadamente $214 \%$ da resistência mecânica quando comparado ao processo sem pré-aquecimento. Este valor corresponde à 9,36\% de eficiência quando comparado à resistência mecânica da liga de alumínio 5052 H34. Os valores de resistência encontrados para as amostras soldadas sem pré-aquecimento e com pré-aquecimento de 250 e $350{ }^{\circ} \mathrm{C}$ são considerados equivalentes para este caso.

Os baixos valores de resistência mecânica encontrados para as juntas soldadas com o deslocamento da ferramenta de $-2,50 \mathrm{~mm}$ podem ser atribuídos à geometria da ferramenta, conforme já relatado anteriormente. A utilização de uma ferramenta com pino cilíndrico poderia minimizar ou corrigir totalmente o problema supracitado para esta condição, uma vez que o contato entre a ferramenta e o aço estaria sempre garantido para qualquer valor de deslocamento da ferramenta maior que zero (offset $>0$ ).

Já para as amostras soldadas com deslocamento da ferramenta igual a zero foram obtidos maiores valores de resistência mecânica. Neste caso, quando a temperatura de pré-aquecimento foi de $450{ }^{\circ} \mathrm{C}$, houve o aumento de aproximadamente $111 \%$ da resistência mecânica quando comparado ao processo sem pré-aquecimento. Este valor corresponde à $47,65 \%$ de eficiência quando comparado à resistência mecânica da liga de alumínio 5052 H34. Foram identificados poucos trabalhos na literatura em que a ferramenta foi posicionada no centro das chapas durante a soldagem dissimilar alumínio-aço. Kimapong e Watanabe [28], por exemplo, obtiveram uma resistência mecânica de aproximadamente $10 \mathrm{MPa}$ durante a soldagem da liga de alumínio 5083 ao aço SS400 com $2 \mathrm{~mm}$ de espessura, o que corresponde a uma eficiência de cerca de $5 \%$ em relação à resistência da liga de alumínio em questão. Karimi et al. [27], por sua vez, alcançaram uma eficiência de cerca de $34 \%$ ao realizar a soldagem da liga e alumínio 1100 ao aço SAE 1045 [27].

O mais comum, entretanto, é soldar o alumínio ao aço com deslocamento da ferramenta em relação à interface. Habibnia et al. [29] atingiram uma resistência à ruptura de $40 \mathrm{MPa}$ ao realizar a soldagem dissimilar da liga de alumínio 5050 ao aço inoxidável 304. Torres López [2], por sua vez, realizou a soldagem dissimilar da liga de alumínio 6063-T5 ao aço AISI SAE 1020, em que o valor máximo da resistência da junta obtida foi de $50 \%$ da liga de alumínio 6063 , quando o deslocamento da ferramenta foi de $+1,5 \mathrm{~mm}$ (Offset $=+1,5$ ). Os resultados obtidos pelo autor foram significativamente menores quando comparados aos resultados de Fukumoto et al. [14] e Sato e Kokawa [30], para as juntas 6063-Aço e 6063-6063 em que foi obtida uma eficiência de $66 \%$ e $62 \%$ da resistência mecânica das ligas de alumínio, respectivamente. Cota e Bracarense [22], por sua vez, alcançaram uma eficiência de cerca de $76 \%$ para a tensão máxima das juntas soldadas da liga de alumínio 5052 H34, quando comparada ao material de base. Fioravanti [24] fez uma lista com diversos resultados de eficiência de juntas soldadas por FSW para diferentes ligas de alumínio, em que os valores variaram de $43 \%$ a $95 \%$, sendo a média de $70 \%$. Estes resultados demonstram que os valores encontrados neste trabalho estão coerentes com os melhores valores de eficiência descritos na literatura para a soldagem pelo processo FSW.

Conforme se apresenta na Figura 12, para cada conjunto de amostras a fratura ocorreu exatamente no mesmo local. Para as amostras soldadas com offset igual a $-2,50 \mathrm{~mm}$ a fratura ocorreu na interface alumínio-aço. Já para as soldas realizadas com offset igual zero, a fratura ocorreu na zona misturada. Nas amostras soldadas com offset igual a zero e com auxílio do pré-aquecimento, a fratura ocorreu na região da zona misturada, em um ângulo correspondente à penetração do aço plastificado no alumínio, que variou de 20 a 60 graus em relação à base de soldagem, identificado por meio de um goniômetro. 


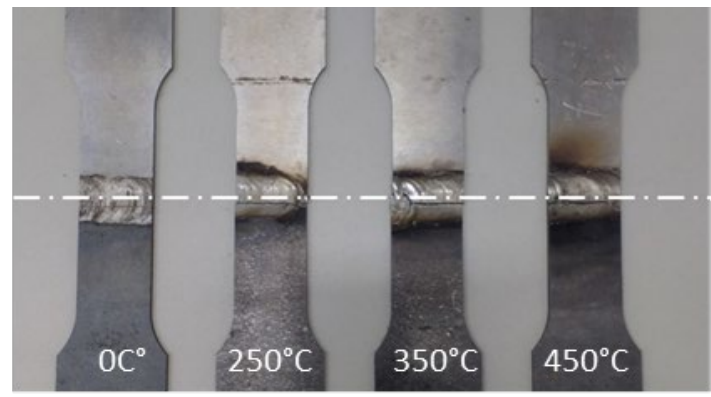

Offset $=-2,50 \mathrm{~mm}$

A

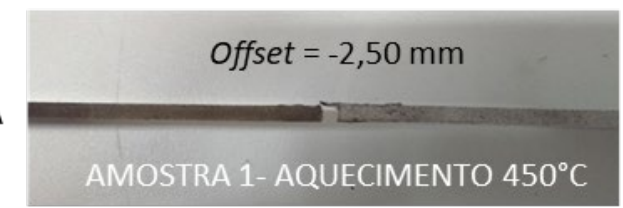

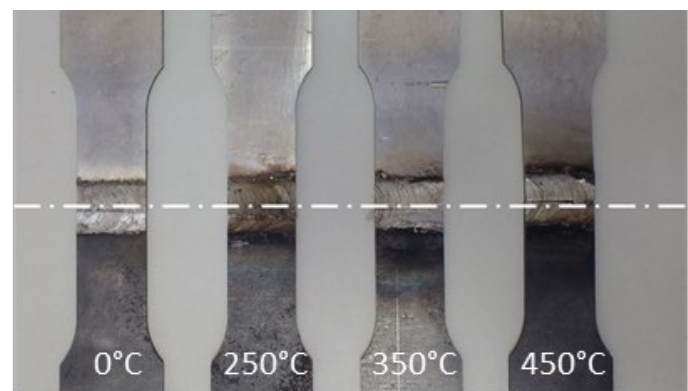

Offset $=0$

B

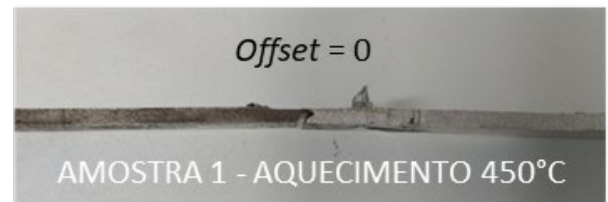

Figura 12. Fratura dos corpos de prova soldados com offset igual a $-2,5 \mathrm{~mm}$ (A) e zero (B) sob diferentes condições de pré-aquecimento.

É apresentado na Figura 13 a síntese dos ensaios mecânicos realizados e apresentados anteriormente. A linha pontilhada representa a interface de soldagem, que auxilia na visualização do deslocamento da ferramenta (offset) de -2,5 mm (1) e zero (2). É possível ver a clara tendência ao aumento da resistência mecânica com o aumento da temperatura de pré-aquecimento, assim como o efeito do deslocamento da ferramenta.

Os corpos de prova são representados na região inferior do gráfico, identificando o modo de falha na secção transversal das amostras na vista lateral. Verifica-se que as amostras soldadas com offset igual a $-2,5 \mathrm{~mm}$ fraturaram predominantemente na interface de soldagem (90 graus). Em contrapartida, as amostras soldadas com offset igual a zero fraturaram predominantemente na zona misturada, em um ângulo que variou de 20 a 60 graus, conforme exposto durante as análises metalográficas.

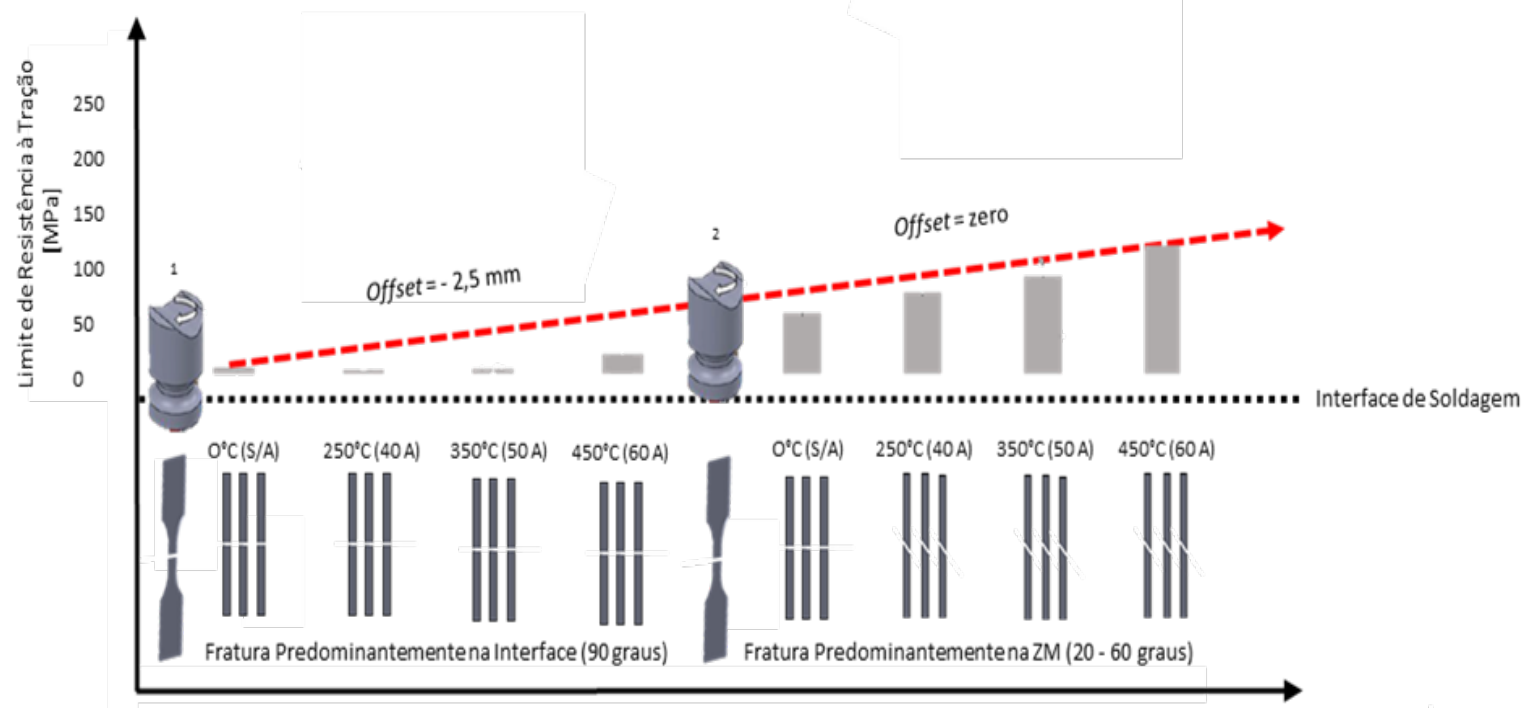

Figura 13. Modo de fratura dos corpos de prova soldados com offset igual a $-2,5 \mathrm{~mm}$ (1) e zero (2) sob diferentes condições de pré-aquecimento.

\section{Conclusões}

Esta pesquisa tratou da primeira soldagem robotizada pelo processo Friction Stir Welding realizado na América Latina, em que foram produzidas juntas soldadas dissimilares do aço carbono SAE 1020 e da liga de alumínio 5052 H34 com 3 mm de espessura. Além disso, foi a primeira aplicação do processo Hybrid Friction Stir Welding na soldagem dissimilar alumínio-aço com a utilização de uma fonte de aquecimento por plasma.

Foi identificado o aumento da resistência mecânica das juntas com o aumento da temperatura de pré-aquecimento, tanto para as amostras soldadas com offset igual a $-2,50 \mathrm{~mm}$, quanto aquelas soldadas com o deslocamento da ferramenta igual a zero. Para as amostras soldadas com deslocamento da ferramenta de $-2,50 \mathrm{~mm}$, quando a temperatura de pré-aquecimento foi de $450^{\circ} \mathrm{C}$, houve $\mathrm{o}$ aumento de aproximadamente $214 \%$ da resistência mecânica quando comparado ao processo sem pré-aquecimento. Este valor 
corresponde à 9,36\% de eficiência quando comparado à resistência mecânica da liga de alumínio 5052 H34. Já para as amostras soldadas com deslocamento da ferramenta igual a zero foram obtidos maiores valores de resistência mecânica. Neste caso, quando a temperatura de pré-aquecimento foi de $450{ }^{\circ} \mathrm{C}$, houve o aumento de aproximadamente $111 \%$ da resistência mecânica quando comparado ao processo sem pré-aquecimento. Este valor corresponde à 47,65\% de eficiência quando comparado à resistência mecânica da liga de alumínio 5052 H34. Salienta-se que este valor de eficiência está próximo aos melhores valores encontrados na literatura para a soldagem dissimilar alumínio-aço.

O aumento da temperatura de pré-aquecimento foi favorável ao aumento da resistência mecânica das juntas dissimilares apresentadas neste trabalho, com redução dos esforços de soldagem e do desgaste da ferramenta. As ferramentas usadas para a soldagem das amostras com pré-aquecimento de 250 e $350{ }^{\circ} \mathrm{C}$ sofreram redução do volume do pino de aproximadamente $90,47 \%$ e $75,39 \%$, respectivamente. Já a ferramenta usada no teste com pré-aquecimento de $450{ }^{\circ} \mathrm{C}$, foi verificado uma redução de apenas $3,44 \%$ do volume do pino.

\section{Agradecimentos}

Os autores gostariam de agradecer ao LRSS (Laboratório de Robótica Soldagem e Simulação) da UFMG, pelo apoio e investimento à pesquisa e ao Centro de Microscopia da UFMG pelo fornecimento dos equipamentos e suporte técnico para os experimentos envolvendo microscopia eletrônica. À COMAU do Brasil pela parceria e empréstimo do robô SMART NJ500, indispensável à essa pesquisa e à empresa Geremia Redutores, pelo apoio à pesquisa por meio da doação do redutor GD49, destinado à adaptação do sistema de soldagem usado neste trabalho. Ao CEFET-MG, por ter cedido as máquinas usadas na fabricação das ferramentas de soldagem e disponibilizado os laboratórios para a execução dos ensaios destrutivos.

\section{Referencias}

[1] Thomas WM. Friction stir butt welding. International Patent Application No. PCT/GB92/0220. 1991.

[2] Torres López EA. Soldagem por atrito com pino não consumível de chapas finas do aço 1020 e da liga de alumínio 6063-T5 [tese de doutorado]. Campinas: Universidade Estadual de Campinas; 2012.

[3] Cabage B. New way to weld. Oak Ridge: Oak Ridge National Laboratory; 2006. (Oak Ridge National Laboratory Reporter; 84).

[4] Casavola C, Cazzato A, Moramarco V. Thermographical analysis of friction stir welding and laser assisted friction stir welding. In: Proceedings of the 13th Youth Symposium on Experimental Solid Mechanics; 2014; Děčín, Czech Republic. Děčín: Institute of Theoretical and Applied Mechanics; 2014. p. 15-19.

[5] Choi D-H, Lee C-Y, Ahn B-W, Choi J-H, Yeon Y-M, Song K, et al. Hybrid friction stir welding of high-carbon steel. Journal of Materials Science and Technology. 2011;27(2):127-130. http://dx.doi.org/10.1016/S1005-0302(11)60037-6.

[6] Kou S, Cao G. Arc-enhanced friction stir welding. U.S. Patent n. 7,078,647. 2006 July 18.

[7] SchegImann G, Palm F, Raether K. Method and device for friction stir welding with simultaneous cooling. U.S. Patent n. 6,772,935. 2004 Aug 10.

[8] Razak MNA. Investigation of heat treatment (preheat) of steel on aluminium-steel welding [degree thesis]. Pahang: Universiti Malaysia Pahang; 2013.

[9] Shah LH, Yusof ASM, Ishak M. Investigation of heat treatment on weld joint quality of stainless steel and aluminium dissimilar welding. In: Proceedings of the 16th International Conference on Advances in Materials \& Processing Technologies; 2013; Taipei, Taiwan. Pfaffikon: Trans Tech Publ.; 2013.

[10] Zargar OA. The preheating influence on welded joint mechanical properties prepared by friction stir welding aluminium alloy $\mathrm{H} 20-\mathrm{H} 20$. Middle East Journal o Scientific Research. 2013;15:1415-1419.

[11] Chen CM, Kovacevic R. Joining of Al 6061 alloy to AISI 1018 steel by combined effects of fusion and solid-state welding. International Journal of Machine Tools \& Manufacture. 2004;44(11):1205-1214. http://dx.doi.org/10.1016/j.ijmachtools.2004.03.011.

[12] Chen T. Process parameters study on FSW joint of dissimilar metals for aluminum steel. Journal of Materials Science. 2009;44(10):25732580. http://dx.doi.org/10.1007/s10853-009-3336-8.

[13] Chen TP, Lin W-B. Optimal FSW process parameters for interface and welded zone toughness of dissimilar aluminium-steel joint. Science and Technology of Welding and Joining. 2010;15(4):279-285. http://dx.doi.org/10.1179/136217109X12518083193711.

[14] Fukumoto M, Mizushima H, Yasui T. Butt welding between dissimilar metals by friction stirring. In: Proceedings of the 5th International FSW Symposium; 2004; Metz, France. Cambridge: TWI; 2004. p. 14-16.

[15] Jiang WH, Kovacevic R. Feasibility study of friction stir welding of 6061-T6 aluminium alloy with AISI 1018 steel. Proceedings of the Institution of Mechanical Engineers. Part B, Journal of Engineering Manufacture. 2004;218(10):1323-1331. http://dx.doi.org/10.1243/0954405042323612. 
[16] Yasui T, Yasui T, Shimoda Y, Tsubaki M, Fukumoto M. Friction stir welding between aluminum and steel with high welding speed. In: Proceedings of the 5th International Friction Stir Welding Symposium; 2004; Metz, France. Cambridge: TWI; 2004.

[17] Capelari TV, Mazzaferro JAE. Avaliação da geometria de ferramenta e parâmetros do processo FSW na soldagem da liga de alumínio AA 5052. Revista Soldagem e Inspeção, São Paulo. 2009;14(3):215-227. http://dx.doi.org/10.1590/S0104-92242009000300005.

[18] Backer J. Feedback control of robotic friction stir welding [doctor thesis]. Trollhättan: University West; 2014.

[19] Almeida DT. Análise microestrutural e avaliação mecânica de juntas soldadas por fricção e mistura mecânica (FSW) da liga de alumínio 5182-O [dissertação de mestrado]. Porto Alegre:Universidade Federal do Rio Grande do Sul; 2015.

[20] Gibson BT. The development of in-process monitoring and control techniques for aerospace applications of Friction Stir Welding [doctor thesis]. Nashville: Vanderbilt University; 2015.

[21] Associação Brasileira de Normas Técnicas. ABNT NBR 6835: alumínio e suas ligas: classificação das têmperas. Rio de Janeiro: ABNT; 2006.

[22] Cota BS, Bracarense AQ. Validation of a newly developed robotic system for friction stir welding process by joining and characterizing joints of aluminum alloy 5052 H34. Soldagem e Inspeção. 2017;22(4):494-510. http://dx.doi.org/10.1590/0104-9224/si2204.08.

[23] Machado AR, Abrão AM, Coelho RT, Silva MB. Teoria da usinagem dos materiais. 3. ed. São Paulo: Blucher; 2015.

[24] Fioravanti AS. Soldagem por FSW de ligas de alumínio Alcalad AA2024-T3 e AA7075-T6 [dissertação de mestrado]. Porto Alegre: Universidade Federal do Rio Grande do Sul; 2008.

[25] American Welding Society. AWS B4.0:2016: standard methods for mechanical testing of welds. New York: AWS; 2007.

[26] Deutsches Institut für Normung. DIN EN ISO 4136: destructive tests on welds in metallic materials: transverse tensile test. Berlin: DIN; 2013.

[27] Karimi N, Nourouzi S, Shakeri M, Habibnia M, Dehghani A. Effect of tool material and offset on friction stir welding of Al alloy to carbon steel. Advanced Materials Research. 2012;445:747-752. http://dx.doi.org/10.4028/www.scientific.net/AMR.445.747.

[28] Kimapong K, Watanabe T. Friction stir welding of aluminum alloy to steel. Welding Journal. 2004;83(10):277.

[29] Habibnia M, Shakeri M, Nourouzi S, Givi MB. Microstructural and mechanical properties of friction stir welded 5050 Al alloy and 304 stainless steel plates. International Journal of Advanced Manufacturing Technology. 2015;76(5-8):819-829. http://dx.doi.org/10.1007/s00170-014-6306-5.

[30] Sato YS, Kokawa H. Distribution of tensile property and microstructure in friction stir weld of 6063 aluminum. Metallurgical and Materials Transactions A: Physical Metallurgy and Materials Science. 2001;32(12):3023-3031. http://dx.doi.org/10.1007/s11661-0010177-8. 